\title{
Una aproximación al uso de la diversidad en el mundo empresarial: Algunas experiencias en las campañas de publicidad de empresas peruanas
}

\author{
Emilio Humberto García Vega \\ MBA, Universidad del Pacífico. Licenciado en Administración, \\ Universidad del Pacífico. Asesor, Consultor, Profesor e \\ Investigador en Estrategia Empresarial. Especialista en \\ Planeamiento, Implementación y Control de estrategias \\ empresariales y de marketing. Autor de los libros ¿Cómo \\ generar valor en las empresas? (2012) y ¿Qué hace especiales \\ a las empresas?: La Ventaja Competitiva a inicios del Siglo \\ XXI (2011), entre otros.
}

\section{Resumen}

En el Perú, aprovechar la diversidad —sobre todo cultural y étnica- y asumirla, es parte de la agenda pendiente de muchos ámbitos y sectores, tengan intereses privados, de gobierno o de otro tipo. En esta línea, uno de los ingredientes que ha detonado el «boom económico» peruano - y que ahora puntualmente lo potencia - es justamente la diversidad. El uso de la misma tiene cada vez una mayor preponderancia en el mundo empresarial peruano. En este sentido, este trabajo presenta una aproximación al uso de la misma en el ámbito de los negocios del Perú para ello se parte de presentar un breve marco teórico con respecto al tratamiento de la diversidad en el ámbito empresarial, luego se desarrolla un diagnóstico acerca del uso de la diversidad en el mundo de los negocios peruano sobre la base de un estudio cualitativo conformado por veinte entrevistas en profundidad desarrolladas a funcionarios con capacidad de decisión en compañías con ventas superiores a los 50 millones de soles anuales y que operan en el Perú. Seguidamente, se presenta cuatro experiencias de empresas peruanas que han empleado la diversidad en sus planes de marketing (en donde la diversidad tiene mayor presencia visible en la concepción del público objetivo y las campañas comunicacionales). Finalmente, se cierra la investigación con algunas conclusiones a modo de reflexión y sugerencia.

\section{Palabras clave}

Estrategia, Marketing, Estrategias de Marketing, Ventaja Competitiva, Diversidad, Perú. 


\section{Objetivos}

En este acápite se presentan los objetivos que sustentan la presente investigación.

\section{Objetivo principal}

El presente trabajo tiene por objetivo principal el establecer una aproximación al uso de la diversidad por parte de las empresas peruanas.

\section{Objetivos secundarios}

- Desarrollar un marco teórico sencillo acerca de la diversidad en el ámbito empresarial.

- Realizar un acercamiento al uso de la diversidad en la práctica empresarial en el Perú.

- Presentar experiencias exitosas de empresas peruanas que emplean la diversidad de forma explícita (en sus planes de marketing).

\section{Metodología}

Para el logro de los objetivos planteados, se diseñó la siguiente metodología:

- En primer lugar, se desarrolla una introducción que presenta el tema motivo de esta investigación.

- En segundo lugar, se realizó una breve revisión bibliográfica que permite presentar un marco teórico con respecto al tratamiento de la diversidad en el ámbito empresarial

- En tercer lugar, se presenta un diagnóstico acerca del uso de la diversidad en el ámbito empresarial peruano sobre la base de veinte entrevistas en profundidad desarrolladas a funcionarios con capacidad de decisión en las estrategias de marketing de sus compañías, las cuales operan en el Perú y que tienen ventas superiores a los 50 millones de soles anuales.

- En cuarto lugar, se identificaron cinco experiencias de empresas peruanas que han empleado la diversidad en sus planes de marketing y se procedió a presentarlas.

- Finalmente, se cierra este trabajo con algunas conclusiones y sugerencias a modo de reflexiones.

\section{Introducción}

Independientemente de discusiones acerca de la situación económica, política y social del Perú; es evidente que se han presentado cambios positivos en los últimos años. Además de elementos estructurales y coyunturales, la asunción de la diversidad como elemento clave de la nacionalidad peruana es un aspecto fundamental en la actualidad que vive esta nación. Mucho de esto, parte de cuándo se empezó a procesar a la diversidad como una fuente de ventaja competitiva. Hecho asumido y aprovechado en la gastronomía y en el turismo, citando a las que posiblemente sean las actividades económicas que presenten mayores perspectivas de crecimiento en el Perú actual.

Aprovechar esta diversidad y asumirla es parte de la agenda pendiente de todos los ámbitos y sectores, tengan intereses privados, de gobierno o de otro tipo. Uno de los ingredientes que ha detonado el «boom económico» peruano -y que ahora puntualmente lo potencia-, es justamente la diversidad.

En el Perú, la diversidad es omnipresente. En el ámbito empresarial los clásicos grupos económicos comparten el protagonismo con otros nuevos, los cuales han surgido de familias cuyo origen es fuertemente provinciano. La distribución del poder económico en el país ha variado. Por ejemplo, las familias Añaños y Flores han construido dos de los paradigmas empresariales más importantes del management nacional: AJE y Topitop. Los Wong son otra familia que desde hace cierto tiempo, juega un rol protagónico en la economía peruana, teniendo actualmente como eje de sus actividades a los Centros Comerciales -después de la venta de todos sus negocios relacionados con los Supermercados a finales del año 2007. La procedencia de estas familias, que se han convertido en los nuevos líderes empresariales del país, son una muestra de la diversidad en función a la variedad de sus orígenes. Así, en los próximos años se cree que se presentará el desarrollo de estos grupos familiares (y otros más) en el mundo de los negocios peruanos en general, lo que implicará un mayor poderío económico de las mismas y una 
representación de estas familias en el espectro empresarial, impensada hace menos de veinte años cuando la gran mayoría de los principales grupos económicos peruanos respondían a un bagaje típicamente aristocrático.

Hace algunos años, el investigador Rolando Arellano (2004) en uno de sus estudios, analizó la categoría "cantantes nacionales» y encontró que en las periferias -0 lo que antiguamente se denominaba como «conos»- los preferidos por el público eran la cantante de folklore nacional Dina Paucar y el grupo local de rock, Líbido. Esto es otra muestra de la diversidad en la que está inmerso el Perú1. Otros ejemplos al respecto, de lo que está ocurriendo en la realidad peruana, es lo que sucede en discotecas como «Aura» y «Gótica» (centros de diversión enfocados a jóvenes adultos de los niveles socioeconómicos altos de Lima). Así, durante los últimos años, conjuntos musicales como el Grupo 5 o Armonía 10 (agrupaciones de orígenes y públicos primarios populares o relacionados con los niveles socioeconómicos más bajos), han desarrollado presentaciones en estos establecimientos. Por poner un espacio temporal, hace diez años era impensado que artistas con expresiones musicales ligadas a la cumbia y cuyo desarrollo artístico tiene una base popular, tuvieran una exposición e impacto tan fuerte en este tipo de espacios de diversión. Antiguamente, la propuesta musical de las discotecas dirigidas a los segmentos más acomodados de lo que se conoce actualmente como Lima Moderna era diferente (orientado a corrientes musicales de origen e influencia anglo o internacional, en general). Otro ejemplo, puede ser el grupo musical Bareto, el cual pasó de ser un conjunto enfocado en un circuito típico de grupos de rock a tomar prestado canciones de la leyenda de la música popular de la selva Juaneco, de manera que los intérpretes de este tipo de música variaron, ya no se trataba de los pobladores de la selva, sino de limeños pertenecientes a la clase media y alta, que además han logrado un éxito contundente en todos los niveles socioeconómicos tocando música popular de la selva. Se puede nombrar también a la serie televisiva Al fondo hay sitio, en ella se puede observar una interrelación entre diferentes grupos estereotípicos que cubren gran parte de la amplitud sociodemográfica existente en el Perú, se trata de un programa que tiene una gran sintonía en casi todos los niveles socioeconómicos. El recorrido por estos episodios de la sociedad peruana puede ser mucho más amplio, así los ejemplos presentados son solo algunas muestras de la presencia cada vez más sólida y frecuente de la diversidad en todos los ámbitos.

\section{Marco Teórico: La diversidad en el ámbito empresarial}

Luego de mencionar en la sección introductoria, algunas evidencias de la relevancia de la diversidad en la sociedad peruana actual; en este acápite se desarrollará un marco teórico cuyo objetivo será el de aproximar el uso de la diversidad en el ámbito empresarial. Para ello, en primer lugar, se presentarán algunas definiciones generales de diversidad con el fin de entender el concepto. En segundo lugar, se plantearán una serie de ideas consideradas como interesantes para aproximarse a la aplicación del concepto de diversidad en el ámbito empresarial. En tercer lugar, se mostrará la aplicación directa de la diversidad en el ámbito empresarial; en este caso, se agruparon los diferentes planteamientos existentes acerca del tema en dos grandes dimensiones (una desde el interior de la empresa y la otra, desde la relación de empresa con sus clientes). Por último, se profundizará en el tema de la rentabilidad del uso de la diversidad en las organizaciones.

\section{IV.1 Definiciones generales}

Como punto de partida del marco teórico se presentarán, algunas definiciones generales

1. Cabe mencionar autores a tener en cuenta para un entendimiento y estudio más profundo del tema desde el punto de vista sociológico y antropológico como Gonzalo Portocarrero, Guillermo Nugent, Oswaldo Medina, Jorge Bruce, Daniel Titinger, entre otros. Sin embargo, se quiere recalcar que este texto está enfocado al uso de la diversidad por parte de las empresas y no pretende desarrollar una discusión sociológica, antropológica o filosófica del tema. 
de diversidad. Esto se realiza para aproximar al lector al concepto estudiado en este trabajo.

- Unesco define «diversidad cultural» como la pluralidad de culturas que coexisten en el mundo; implica, por un lado, la preservación y promoción de las culturas existentes y, por el otro, el respeto hacia otras culturas. En este sentido, la diversidad cultural es uno de los pilares del desarrollo sostenible, está relacionada con la identidad de las personas y las sociedades, con la democracia como expresión de la libertad y con el acceso de los ciudadanos a las obras de creación, especialmente a las que se producen en su región. Crea las condiciones necesarias para un diálogo entre diferentes culturas y permite así el enriquecimiento mutuo de las culturas. Esta organización afirma que el respeto de la diversidad cultural y de las civilizaciones contribuye igualmente a la promoción de una cultura de paz (Kaluf 2005).

- El concepto de diversidad abarca aceptación y respeto. Además, se debe entender también que cada individuo es único, y reconocer las diferencias individuales de cada persona. Estas disimilitudes puede ser en las dimensiones racial, étnica, de género, de orientación sexual, nivel socioeconómico, edad, habilidades físicas, creencias religiosas, ideas políticas, u otras ideologías. Asimismo, es importante la exploración de estas diferencias en un ambiente seguro, positivo y enriquecedor. Se trata de entendernos unos a otros y movernos más allá de la simple tolerancia a abrazar y celebrar las ricas dimensiones de la diversidad inherente en cada individuo (Queensborough Community College s.f.)

- La diversidad cultural es cada vez más empleada y se define en relación con la variación social y cultural; de la misma manera como la "biodiversidad» se utiliza para referirse a las variaciones ecológicas, los hábitats y los ecosistemas biológicos y ecológicos. Un intento de definir explícitamente la diversidad, a través de este enfoque, es concebirla como «una situación que incluye la representación de varios grupos (idealmente todos) dentro de un entorno determinado, como una universidad o un centro de trabajo. Esta palabra se refiere más comúnmente a las diferencias entre los grupos culturales, aunque también se utiliza para describir las diferencias dentro de los grupos culturales. Se debe hacer énfasis en la aceptación y el respeto de las diferencias culturales, reconociendo que ninguna cultura es intrínsecamente superior a otra» (Dietz 2007).

\section{IV.2 Ideas interesantes del uso de diversidad en el ámbito empresarial}

En este apartado se presentarán algunas definiciones o ideas relevantes que aproximen el concepto de diversidad enfocado en el mundo empresarial.

- La diversidad en un lugar de trabajo puede reflejarse a través de niveles. Se dice que el ambiente laboral es diverso a nivel personal cuando son las características individuales las que difieren: raza, género, orientación sexual, nacionalidad y habilidades físicas y mentales. Dentro del nivel individual existen otras características secundarias como el nivel de educación, valores y creencias. Una organización es diversa a nivel organizacional cuando se habla de heterogeneidad en posiciones jerárquicas, permanencia en el empleo, o tipo de trabajo (a medio tiempo o tiempo completo) (O’Flynn, Sammartino, Lau y Nicholas 2001).

- La diversidad no sólo se refiere a tratar con diferencias o similitudes sino tratar con ambas simultáneamente. Los elementos que no pueden ser cambiados (género, raza, edad, etnia, entre otros) forman parte de nuestra diversidad por naturaleza; por otra parte, los elementos que sí pueden ser cambiados (locación geográfica, ingreso, trabajo, estilo de vida, nivel económico, etcétera) están incluidas en una definición más amplia de diversidad. Finalmente aspectos relacionados en las firmas afectan 
la cultura individual y organizacional (McDonald 2003).

- La inclusión en el ámbito laboral puede ser descrita de diferentes maneras, para Mor-Barak and Cherin (1998) puede ser descrita como el "grado en el que los individuos se sienten parte de un proceso organizacional», generado por su acceso a los recursos, trabajos de grupo, y habilidad para incluir en la toma de decisiones.

- El proceso de globalización ha tenido grandes efectos sobre la fuerza laboral, fomentando su carácter migratorio. Esto a su vez ha resultado en una mayor diversidad dentro de las organizaciones, de tal manera que los grupos minoritarios puedan recibir iguales oportunidades de desarrollo que los grupos dominantes. Inicialmente las firmas se adhirieron a este concepto sólo por cumplir con una serie de requerimientos legales, sin embargo hoy en día la creencia que predomina es que la diversificación de la fuerza laboral es una ventaja competitiva que permite acceder a una serie de beneficios como el acceso a un rango mayor de información, mejores decisiones, mejores soluciones a los problemas y más innovación (Ollapally y Bhatnagar 2009).

- Una fuerza laboral diversa puede ser entendida como aquella que se distingue por la presencia de muchas religiones, culturas, color de piel, capacidades, y que involucra personas de ambos sexos con diferentes orientaciones sexuales (Miller y Rowney 2005). Otro punto de vista acerca de la diversidad es que su concepto necesita ser redefinido (Hewlett, Lucas y West 2005) para incorporar otros elementos además de la inclusión, ya que la diversidad también está asociada a la creación de una cultura donde las minorías puedan sentirse aceptados y expresarse libremente (Robinson y Dechant 1997).

- Algunos autores afirman que tener una fuerza laboral diversa permite a la organización ser representativa de sus clientes en el mercado (Thomas y Kanji
2004), tener múltiples perspectivas que llevarán a una mejor toma de decisiones (Dahlin 2005; Allen 2004); así como ideas más innovadoras (Vedpuriswar 2008; Dahlin, Weingart y Hinds 2005; Grosch y Doherty 1999). Como consecuencia de la diversidad aumentará la productividad, y con esto el mejor desempeño y crecimiento del negocio (Robinson y Dechant 1997).

- Se dice que las organizaciones que desarrollan iniciativas para fomentar la diversidad obtienen mayor reconocimiento y prestigio en relación a sus competidores. Dado que el mundo de los negocios puede ser muy incierto, manejar correctamente la diversidad puede ser visto como apoyo al talento (Robinson y Dechant 1997; Grosch y Doherty 1999; Forbes 2008). Además, la diversidad en la empresa puede ser beneficiosa en términos financieros ya que reduce los costos de la rotación de personal (Sub y Kleiner 2008; Groschl y Doherty 1999; White 2000; Cox y Blake 1991; Robinson y Dechant 1997).

- Por otro lado, hay quienes plantean que en las organizaciones en donde no se desarrolla o reconoce la diversidad, las minorías se sienten separadas del resto de la empresa (Heames, Harvey y Treadway 2006; Bryan 2000), y los niveles de ausentismo y rotación del personal aumentan (Robinson y Dechant 1997; Tsui, Egan y O' Reilly 1992). Igualmente, estas personas muestran un menor compromiso y una mayor intención de abandonar el puesto. La comunicación y la creatividad se reducen (Cox y Blake 1991), mientras que el nivel de estrés aumenta (Heames, Harvey y Treadway 2006), debido al esfuerzo que hacen estos grupos por pertenecer a la «mayoría». Todo lo mencionado anteriormente causa una enorme pérdida de talento (Donkin 2007; Nyambegera 2002; Bryan 2000; Cox y Blake 1991).

\section{IV.3 Dimensiones en el uso de la diversidad en las organizaciones}

En cuanto a la aplicación directa de la diversidad en el ámbito empresarial, existen diferentes 
planteamientos, los cuales se podrían agrupar en dos dimensiones. La primera se refiere al manejo interno («hacia dentro») de la diversidad en las organizaciones; en ésta el tema de recursos humanos es el eje principal de discusión. La segunda tiene que ver con el manejo externo («hacia afuera») de la diversidad en las empresas, relación que se presenta primordialmente cuando una organización establece contacto con sus clientes. Esta última dimensión se presenta, mayormente, en las labores de Marketing o similares.

- Manejo interno de la diversidad («hacia dentro»), estudios de la Universidad de Tennessee en los EE.UU., sostienen que la percepción de los empleados de la diversidad en la alta gerencia está positivamente relacionada con la percepción de la performance organizacional. Asimismo, se puede afirmar que la percepción de los empleados respecto de la diversidad dentro de los mandos medios en una empresa también está relacionada positivamente con la performance de la organización (Allen, Dawson, Wheatley y White 2007). En este sentido, se percibe que la diversidad de los equipos gerenciales, está positivamente relacionada con mejores performances dentro de las empresas.

Schmidt (2004), afirma que la diversidad también puede estar relacionada con la gestión eficiente de las empresas. En los últimos años, Canadá ha sufrido grandes cambios a nivel demográfico lo que originó que las compañías reformulen sus programas de entrenamiento y capacitación de sus empleados. Así, la diversidad asume un rol muy relevante en los mismos, siendo su meta principal el correcto entendimiento de los diversos valores de las diferentes culturas involucradas en las organizaciones. El autor asevera que la diversidad en la gestión asume un rol estratégico; en esta línea, algunas características de un programa eficiente, son: a) la relación con un objetivo de negocio, b) no se puede dar preferencias entre los distintos grupos que se presentan en una empresa, y c) debe estar apoyado por la alta gerencia de forma plena y rotunda.

El mismo autor sostiene que debe presentarse un liderazgo efectivo de la diversidad desde dentro de la empresa para luego poder plantear un manejo de la misma hacia el mercado. Si se logra esto, se forjará una mejor comunicación con agentes exógenos y endógenos de la empresa, se ampliará la base de clientes y se asegurará la consolidación de relaciones interraciales e interculturales efectivas.

Algunos autores enfrentan el tema con un enfoque diferente: no tratan acerca de la diversidad, sino más bien de un sentido de pertenencia a una cultura; a algo que los miembros de las comunidades - a pesar de ser diferentes- pueden compartir y tener una relación emocional de inclusión.

Keith D. Denton (1997) manifiesta que una cultura en común ayuda a las personas a darle un sentido a las cosas, y las define como seres humanos. Desde su punto de vista, este sentido de pertenencia está más que nada ligado a la cultura interna de una empresa, es decir, ese conjunto de valores e ideas que una compañía comparte. Así, dejar que uno se defina a sí mismo por su ocupación o departamento en vez de hacerlo por la misma empresa, es un error muy peligroso para las compañías. Denton hace hincapié en el hecho de que no debemos concentrarnos en lo diferentes que somos, sino en lo que compartimos. Este es el caso de la empresa Xerox y lo que llamaron el "proceso Xerox 2000», que se produjo entre 1989 y 1992, cuyo fin era forjar una identidad cultural dentro de la empresa tomando en cuenta cómo es que sus empleados realmente se comportaban en vez de preguntarse cómo es que deberían comportarse. Resulta interesante lo que menciona este autor, ya que muchos países latinoamericanos, son muy diversos culturalmente, pero comparten sentimientos de pertenencia entre sus habitantes, lo que define sus sentimientos de nacionalidad pero muy diversos en niveles socioeconómicos y género. 
Otro punto a detallar es el rol que cumplen las fuerzas laborales dentro de los negocios. La diversidad de este factor productivo ha jugado un rol importante en los últimos años. Bajo el contexto de una economía globalizada, las firmas se han apresurado en crear ambientes de trabajo más inclusivos. Sin embargo, muchas de esas organizaciones se han "decepcionado» de los resultados obtenidos al no considerarlos significantes (Cox 2001).

Una explicación para lo anterior es que las firmas han centrado mucha atención en la dimensión de políticas, sistemas y procesos; y han dejado de lado el marco normativo, lo que constituye un error, ya que la diversidad tiene como elementos fundamentales a las normas culturales y valores. Una manera de reparar esta situación es estableciendo una cultura de inclusión, que puede entenderse como un ambiente organizacional que permita que personas con múltiples conocimientos, mentalidades y formas de pensar, sean capaces de trabajar juntas y que su desempeño alcance el máximo potencial, cumpliendo con los objetivos de la firma (Pless y Maak 2004). Para que este ambiente inclusivo se desarrolle se requiere de los siguientes «principios fundamentales»:

\} El reconocimiento mutuo es el principio básico para el desarrollo de la inclusión; este principio afirma la aceptación y coexistencia con los demás.

El reconocimiento puede separarse en tres áreas: emocional, legal y política y solidaria (Honnet 1994; Maak 1999). El primero es el más importante e implica que las organizaciones necesitan prestar mayor atención a los requerimientos emocionales de su fuerza laboral, a través de palabras, gestos y compromisos. El segundo hace referencia al estado de igualdad dentro de la firma, donde todos los trabajadores posean los mismos derechos y sean considerados como "ciudadanos igualmente libres» dentro de la organización. Finalmente, el tercero tiene mucho que ver con el último mencionado, ya que si las personas son reconocidas como diferentes, pero a la vez iguales, son capaces de ser ellos mismos, y estar motivados a dar los mejor de sí. Este hecho conlleva a que el personal pueda practicar el reconocimiento solidario con otros miembros de la organización, trabajando juntos y generando confianza entre sí.

\} Otro elemento relevante es el «entendimiento recíproco», que busca conocer a cada miembro de la organización como alguien con el que se puede comunicar abiertamente, incrementando los niveles de información internos.

\} La integración de diferentes puntos de vista es otro principio fundamental. No obstante, la presencia de diversidad de los puntos de vista no garantiza la participación integral de la fuerza laboral, ya que generalmente las opiniones que contrastan están asociadas con una distribución desigual de poder entre grupos, entonces la opinión del grupo dominante prevalece sobre la del grupo marginado.

\} Cómo ultimo principio fundamental se encuentra la confianza. Este principio empuja a que la fuerza laboral multicultural trabaje de una manera cooperativa, compartiendo conocimientos, experiencias y puntos de vista (Calton y Kurland 1996). Existen contextos que facilitan que este principio se desarrolle en el ambiente de trabajo, como aquellos basados en proximidad, cooperación, y reconocimiento mutuo. Para una cultura de inclusión, la integridad de la fuerza laboral es tan importante como la confianza (Pless y Maak 2004).

Todos los principios anteriormente mencionados representan un desafío para las organizaciones que a su vez implica un cambio trascendental. En teoría, es sencillo estar de acuerdo y aceptar que 
estos fundamentos son favorables para un ambiente de inclusión, pero ponerlos en práctica requiere de una transformación integral que puede seguir las siguientes etapas (Pless y Maak 2004):

\} La primera etapa se puede dividir en dos pasos; el primero involucra tomar conciencia de la pluralidad de los puntos de vista y poder integrar todas las diversas opiniones en un solo discurso (Gilbert y Ivancevicj 2000). El segundo paso consiste en crear una base común de entendimiento, identificando los aspectos morales principales, y los patrones de pensamiento y comportamiento específicos.

\} Después de haber generado conciencia sobre el tema, es importante desarrollar una visión de inclusión (Gouillart y Kelly 1995; Kotter 1996). Para crear un ambiente multicultural es necesario: asegurarse de que el contexto laboral esté libre de cualquier tipo de acoso o agresión; crear una cultura de comunicación basada en la confianza y comprensión de diversas opiniones; proveer al personal de igualdad en derechos y oportunidades para que puedan desarrollarse completamente y alcanzar su máximo potencial.

\} La tercera etapa consiste en el replanteamiento de conceptos claves en la administración de la organización. Un concepto fundamental es el rol del líder, que actualmente es visto como un mentor y guía de los empleados, que busca tener una relación cercana a ellos. Además, se debe dejar de ver a los trabajadores como un recurso y comenzar a valorarlos como seres humanos productivos (Pless y Maak 2004).

- Manejo externo de la diversidad («hacia afuera»), La diversidad cultural se puede manifestar claramente dentro del marketing cuando, en las estrategias de segmentación, las empresas hacen uso de la misma dentro de los criterios en la definición de un segmento. Así la diversidad cultural no solo ha cambiado la forma de hacer negocios, sino también la forma de conceptualizar los mercados. Según Cui y Choudhury (2002), «[...]en los EE.UU., las minorías étnicas para inicios del siglo XXI representaban casi el $25 \%$ de la población total y se predice que alcanzarán un $47.2 \%$ alrededor del año 2050. El poder de consumo de los afroamericanos, hispanoamericanos y asiáticos americanos combinados ya ha alcanzado el trillón de dólares, por lo que se les llama los «mercados americanos emergentes». Para Cui Esto ha producido un enfoque diferente en el marketing; de forma que para la primera década del siglo $X X I$, se hace referencia a una «segmentación subcultural» y a un targeted marketing, para poder llegar adecuadamente a estos consumidores y comunicarles directamente los mensajes definidos. Cui y Choudhury presentan resultados en sus investigaciones que indican cómo la segmentación por etnias puede ser eficiente en cuanto a costos y puede contribuir de forma efectiva al crecimiento, rendimiento y competitividad de una compañía. Sin embargo, los mencionados autores sostienen que este hecho puede no ser del todo beneficioso para las empresas ya que está comprobado que una comunicación mucho más directa al público objetivo genera una mejor respuesta hacia una campaña específica, pero el costo de identificar al mismo podría sobrepasar los ingresos que por dicha campaña, la empresa genere.

En países como Inglaterra donde la inmigración de asiáticos e hindúes es muy elevada, se ha desarrollado lo que se conoce como «Marketing Étnico» (dirigirse y separar el mercado por etnias). No obstante, un estudio realizado por Sonny Nwankwo y Andrew Lindridge (1998) demuestra que el Marketing Étnico no puede ser exitoso, a menos que se haga de forma estratégica. Mostrar algunas caras, rostros o características de las minorías étnicas en los productos o en comerciales 
de televisión no resultaría suficiente. Las compañías que se dirigen a dichas minorías deberían trabajar en relaciones de largo plazo con dichos grupos ya que la penetración de mercados étnicos necesita de compromisos de largo plazo. Para ello, es pertinente preguntarse si es necesario hacer una campaña de Marketing diferente para cada uno de los grupos étnicos distintos a los cuales una empresa se dirige. Según los mencionados autores, no es necesario. Lo que se debe tomar en cuenta es el reconocimiento e inclusión de características étnicas específicas y no estereotípicas en campañas de marketing lo cual —según ellos- aumentará la credibilidad de la empresa y promoverá una mejor actitud hacia la marca dentro de un grupo étnico específico. No obstante, el Marketing étnico también puede servir para encontrar ventajas competitivas en nichos de mercado o inclusive en mercados saturados además de ser muy útil para desarrollar una relación mucho más cercana con los consumidores en nuevos mercados.

El uso de elementos culturales en la publicidad y el marketing dirigido a las minorías puede ser bastante beneficioso, pero esta inclusión no es garantía de éxito comercial. David Burgos (2008) manifiesta que el mal o excesivo uso de este tipo de herramientas, podría ser contraproducente y afectar la percepción de los consumidores respecto a la marca de un producto. En primer lugar, los encargados de una campaña de marketing deben asegurar que su publicidad multicultural es fácil de entender y atractiva; que genera las asociaciones deseadas con la marca y que motiva a los consumidores a actuar de una $\mathrm{u}$ otra manera. No obstante, hay mucha evidencia que constata que la publicidad dirigida a un grupo en específico es, por lo general, más efectiva que la regular. Así, el problema es que muchos de los profesionales se concentran demasiado en los elementos culturales de su campaña y pasan por alto los elementos que una campaña publicitaria debería tener para internalizar el mensaje en la mente de los consumidores. De esta manera, es más importante el contenido que el formato en sí de la campaña publicitaria ya que, al fin y al cabo, no se debe olvidar que, sin importar lo étnico; las personas son -ante todo- consumidores que buscan atributos en productos y servicios. Así, se debe priorizar la comunicación de estos atributos y luego buscar la posibilidad de ver si pueden ser culturalmente relevantes y aprovechar elementos relacionados con lo étnico o lo diverso culturalmente.

Gina A. Rudan (2004), Directora de PR Newswire para mercados multiculturales e internacionales, define cinco reglas elementales para lanzar una estrategia multicultural a nivel estratégico y funcional:

\} La integración es la clave. Hace más de dos décadas, el proceso para alcanzar mercados multiculturales se basaba en esfuerzos unidimensionales tal como la traducción literal de las campañas de marketing. En la actualidad, las organizaciones están desarrollando productos diseñados para satisfacer las nuevas necesidades, además de crear departamentos multiculturales, asignando presupuestos de marketing por segmento $y$, lo más importante, poniendo metas mesurables para cada segmento. Estatendencia estágenerando retornos importantes. Asimismo, no se debe olvidar la integración de Relaciones Públicas con la Publicidad. La división entre ambas es un error muy grave.

\} Hacer una investigación de mercados ad hoc. Investigación demográfica, psicográfica y conocer la parte sociológica es elemental para la preparación de la estrategia de marketing. La investigación puede ser costosa, pero es elemental para que la estrategia sea exitosa. Se debe estudiar cuidadosamente el segmento y su relación con sus productos o servicios. 
Entender los pormenores culturales de un mercado antes de empezar con el diseño de un plan de marketing y una campaña publicitaria, es muy importante.

\} Conectividad cultural. Se refiere a la capacidad de llegar a un consumidor en su contexto cultural. Algunos conectores a considerarse son: valores, comunidad, religión, estilo de vida, etnicidad, raza, orientación sexual, nivel socioeconómico, país de origen e idioma. La meta es conectarse de forma íntima con ambos (comunidad e individuos).

Percepción es realidad. La manera en la cual las comunidades perciben a una compañía, definirá cómo los individuos la verán. La percepción de un consumidor respecto de un producto será la realidad de este último. Este concepto básico de marketing es fundamental en el campo multicultural y la mejor forma de lograr una percepción positiva es el mantener buenas relaciones con organizaciones étnicas. Porejemplo, muchosejecutivosde marketing norteamericanos mantienen una relación estrecha con La Raza, una de las más grandes organizaciones hispanas sin fines de lucro avocadas a mejorar las oportunidades de los hispanos en los EE.UU.

\} Agruparse con los expertos.. Durante la última década, servicios culturales especializados (consultorías, relaciones públicas, publicidad e investigación), han visto un crecimiento importante en los segmentos multiculturales. Al planear una campaña, se debe identificar los recursos adecuados y contratar una agencia experta en el tema.

\section{IV.4 Rentabilidad tras el uso de la diversidad en las organizaciones}

Finalmente, un tema muy relevante en el estudio y uso de la diversidad en las organizaciones se refiere a si ésta es rentable o no para las mismas. Aquellos que están a favor de la diversidad sostienen que «la diversidad paga» (Hubbard 2004; Cox y Bale 1997) ya que mejora la calidad de los bienes y servicios, genera una mayor participación en el mercado, y ayuda a conocer las necesidades de los clientes (Hubbard 2004). Por otra parte, aquellos que están en contra argumentan que la diversidad (racial y étnica) genera conflictos entre los trabajadores (Skerry 2002), reduce la cohesión del grupo, y aumenta los niveles de ausentismo y rotación del personal (Tsui, Egan y O’Reilly 1992).

Ante este debate Cedric Herring (2009), mediante un estudio se trató de determinar el efecto real de la diversidad racial en la fuerza laboral sobre el desarrollo de la organización. Para poder llevar a cabo un análisis exhaustivo, se tomaron en consideración las siguientes hipótesis:

- Hipótesis 1: A mayor diversidad racial de la fuerza laboral, el volumen de ventas de la firma será mayor.

- Hipótesis 2: A mayor diversidad racial de la fuerza laboral, la firma tendrá mayor cantidad de clientes.

- Hipótesis 3: A mayor diversidad racial de la fuerza laboral, la firma poseerá mayor participación en el mercado.

- Hipótesis 4: A mayor diversidad racial de la fuerza laboral, la firma recibirá mayores ganancias en relación a sus competidores.

Para tal fin, se trabajó con data proveniente de la Encuesta Nacional de Organizaciones (USA) de 1996-1997 (Kalleberg, Knoke and Marsen 2001). Dicha encuesta se aplicó a una muestra aleatoria de 1002 establecimientos de trabajo de un total de 15 millones. Para cumplir con los objetivos de este trabajo se analizan los datos de 251 empresas con fines de lucro que proporcionaron información acerca de: composición racial, volumen de ventas, número de clientes, participación de mercado y rentabilidad.

De forma resumida, en el estudio de Cedric Herring (2009), se utiliza como variable de análisis el Índice de Diversidad Racial (RID) (Bratter y Zuberi 2001), que estima la probabilidad de que dos individuos que sean escogidos aleatoria e independientemente pertenezcan a diferentes grupos raciales. Este índice puede ser definido también como una medida de concentración de diferencia racial en la población. Dado que este 
indicador tiene limitaciones, entonces se utiliza su equivalente corregido: el Índice asimétrico de Diversidad Racial (ARID). Asimismo, las variables dependientes fueron: volumen de ventas, clientes, participación de mercado y rentabilidad. Mientras que las variables de control fueron: forma legal de la organización, qué porcentaje de su fuerza laboral son mujeres, tamaño y edad de la organización. Los resultados relevantes para este trabajo de investigación fueron los siguientes:

- Las empresas que tienen una mayor diversidad racial en su fuerza laboral están asociados a mayores niveles de venta, mayor número de clientes, mayor participación de mercado y un nivel mayor de rentabilidad.

- Las empresas que tienen menor diversidad racial son en su mayoría individuales, o de asociaciones únicas, mientras que las empresas con mayor diversidad tienden a ser corporaciones.

- Organizaciones con menor diversidad racial tienen un mayor porcentaje de fuerza laboral femenina que las organizaciones con mayor diversidad racial.

- La diversidad racial en la fuerza laboral está asociada a un mayor número de trabajadores.

- Las firmas con baja diversidad racial tienen menor antigüedad que las de mayor variedad racial.

Estos resultados no indican mucho acerca del impacto de la diversidad sobre la organización, por lo que se analizó adicionalmente la relación de cada variable (en logaritmos) con el nivel de diversidad racial en las organizaciones, en dos modelos, uno simple, y el segundo donde se incluían otros factores de control. Con estos cambios en las variables se obtuvieron resultados de mayor envergadura:

- La relación entre diversidad racial y volumen de ventas es significante, incluso cuando otros factores se introducen al modelo, lo cual respalda la hipótesis 1 ( «a mayor diversidad racial de la fuerza laboral, el volumen de ventas de la firma será mayor»).
- La diversidad racial y el número de clientes están positivamente relacionados y se mantiene constante a pesar de la introducción de otras variables de control; esto confirma la hipótesis 2 («a mayor diversidad racial de la fuerza laboral, la firma tendrá mayor cantidad de clientes»).

- La participación de mercado de las firmas y la diversidad en su fuerza laboral mantienen una relación directa, limpiando los efectos de otros componentes como: la naturaleza de la organización, tamaño y edad. Estos datos son consistentes con la hipótesis 3 («a mayor diversidad racial de la fuerza laboral, la firma poseerá mayor participación en el mercado»).

- La rentabilidad relativa aumenta cuando se compara con la diversidad racial, y estos resultados se mantienen a pesar de la aparición de otros elementos; por lo que se puede afirmar que la hipótesis 4 es verdadera («a mayor diversidad racial de la fuerza laboral, la firma recibirá mayores ganancias en relación a sus competidores»).

- La rentabilidad relativa aumenta cuando se compara con la diversidad racial, y estos resultados se mantienen a pesar de la aparición de otros elementos; por lo que se puede afirmar que la hipótesis 4 es verdadera («a mayor diversidad racial de la fuerza laboral, la firma recibirá mayores ganancias en relación a sus competidores").

Todos estos resultados son consistentes y sugieren que la diversidad de la fuerza laboral tiene un efecto positivo sobre el desempeño de la organización. Esta asociación positiva entre diversidad y comportamiento organizacional puede deberse a que los grupos inclusivos sean más talentosos, o que las firmas exitosas puedan dedicar mayores de recursos a los temas de diversidad, o se puede deber a una razón dinámica que involucre ambos aspectos. Lo que sí se puede afirmar debido a la comprobación de las cuatro hipótesis planteadas anteriormente, es que efectivamente existe un impacto positivo de la diversidad racial en la fuerza laboral sobre 
la comunicación, la creatividad y resolución de problemas, que finalmente incrementa la rentabilidad y las ganancias de la firma (Herring, 2009).

Por todos los hechos desarrollados en los párrafos anteriores, no resulta inverosímil afirmar que, en el mundo de los negocios, la diversidad posee una gran importancia sea como parte de la gestión de las organizaciones como en su relación con sus consumidores y más aún - tema no profundizado en este escrito- con sus stakeholders. En definitiva, no se pude dudar que la diversidad juega un rol importante dentro de cada organización; puesto que, involucra tanto el bienestar de los recursos humanos y la creación una conexión con los clientes. En otras palabras, se puede afirmar que es posible utilizar de una manera adecuada este concepto «hacia afuera» y «hacia dentro» de cada empresa y que su gestión adecuada podría aumentar la rentabilidad tal como lo demostró el estudio empírico presentado en este texto. Se trata entonces de un tema vigente y cada vez más relevante para las gerencias actuales.

\section{Una aproximación a la diversidad en el marketing peruano: Un estudio cualitativo a ejecutivos peruanos de empresas con ventas superiores a los $\mathbf{5 0}$ millones de soles}

Somos un país multicultural, plural, mega diverso por nuestro clima, topografía, religiones, colores de piel, costumbres... Somos un país bien complicado Opinión de ejecutivo entrevistado para la presente investigación

Para tratar lograr un acercamiento al uso de la diversidad en el mundo empresarial peruano, se realizaron veinte (20) entrevistas a igual número de ejecutivos de empresas de diferentes rubros (bancos, consumo masivo, bebidas, retail, telecomunicaciones y turismo $)^{2}$. Las empresas elegidas presentan ventas superiores a los cincuenta millones de soles anuales. Se trató de funcionarios con capacidad de decisión en las estrategias de sus compañías. Los resultados de la aplicación de las mismas y su posterior análisis, sirven para tener un acercamiento al panorama acerca del uso de la diversidad en el ámbito empresarial y del marketing peruano. Resulta muy interesante tener una aproximación a la diversidad de quienes están en el día a día empresarial desde sus gerencias y jefaturas. Para una mejor obtención de la información, posterior análisis de la misma y presentación de los resultados, se trabajó sobre la base de seis temas, los cuales se exponen a continuación:

\section{- Definición de diversidad}

Es decir, se trata de obtener una definición del término (mediante la pregunta: ¿qué es diversidad para usted?). En este punto se logra que los propios entrevistados establezcan un alcance acerca de lo qué es la diversidad para ellos. No se quiso partir de una definición específica y / o científica, sino que más bien, se buscó que los propios ejecutivos dieran una manifestación acerca del tema desde su punto de vista pragmático y orientado al quehacer empresarial.

- Uso de la diversidad en el mundo empresarial peruano

En esta parte se genera un acercamiento al uso de la diversidad de las empresas en el Perú de forma general $\mathrm{y}$, específicamente, por las compañías en las que laboran (Esto se logró mediante la interrogante: ¿Creen que las empresas peruanas hacen uso de la diversidad?, y ¿su empresa emplea la diversidad en su desarrollo?).

- Tipo de diversidad empleado por las empresas peruanas

En este acápite se conoció el tipo de diversidad que se incluye en sus organizaciones (en este caso la pregunta formulada fue: ¿Qué tipo de diversidad incluyen las empresas en sus labores (raza,

2. Las entrevistas fueron realizadas entre los meses de junio y octubre de 2012. En lo referente a lo jerárquico; 12 entrevistados tenían en nivel de gerentes y ocho el cargo de jefe. 
género, identidad sexual, regiones, clases sociales, edad, entre otros)?).

- Rentabilidad del uso de la diversidad

En este punto se define la opinión de los entrevistados en cuanto la rentabilidad del uso de la diversidad en sus organizaciones (Se trabajó con la pregunta: ¿Es rentable el uso de la diversidad en los diversos planes que desarrollan las empresas en el Perú?).

- Retos que plantea el uso de la diversidad En este acápite, se desarrollan los retos que se plantean para los ejecutivos en relación con el tema.

- Aporte del auto - reconocimiento de la diversidad peruana

En este punto se definirá —desde el punto de vista de los entrevistados - cómo aporta del auto-reconocimiento de la diversidad a la sociedad y al ámbito empresarial peruanos.

Seguidamente, se muestran los desarrollos de cada tema planteado ${ }^{3}$ :

\section{i) Definición de Diversidad}

En el ámbito de la definición del término «diversidad» por parte de los ejecutivos, todos aluden a elementos de diferente naturaleza (cultural, racial, entre otros) que determinan la citada diversidad. Específicamente, se tiene lo siguiente.

- Existe la idea de que la diversidad es un concepto útil dentro de la estrategia de segmentación de las empresas por lo que es necesario tenerla presente en las decisiones de marketing de las compañías.

- Se podría definir la diversidad como:

\} La presencia de elementos, características y realidades diferentes.

\} Un fenómeno que se manifiesta en la convivencia en lugares comunes de personas de diferentes procedencias socioculturales.

\} La conciencia de que en una sociedad existen diversas subculturas en función de aspectos étnicos, sociales y generacionales.

\} La variedad y mezcla de culturas, razas, sabores y colores.

- Los entrevistados afirman que la diversidad no está solamente relacionada con la raza, la cultura, el lugar de nacimiento ni de residencia, y con el poder adquisitivo. La misma se está relacionada con:

\} El reconocimiento de distintas costumbres dentro de la amplia gama que ofrece el Perú.

\} La cantidad de regiones y climas que existen en el Perú.

\} Una idea compartida por los entrevistados es que resulta muy importante para el ejecutivo peruano; el tener en cuenta las raíces milenarias del país, sus diversas etnias, sus climas y tipos de ambientes naturales, la extraordinaria variedad de formas vivientes en el país, y su mega diversidad desde el punto de vista geográfico.

Los entrevistados son conscientes de la diversidad y la ubican principalmente en el ámbito cultural. Todos han manifestado la variedad presente en el Perú a todo nivel de manera que tratar acerca del tema de diversidad fue bastante sencillo $y$ directo. En suma, se puede firmar que exista un acercamiento al tema por parte de las personas de mercado de las empresas.

ii) Uso de la diversidad en el mundo empresarial peruano

En este punto se solicitó una evaluación acerca de cómo las empresas peruanas están empleando la diversidad en sus labores, así se obtuvo el siguiente diagnóstico.

- Actualmente la publicidad está haciendo más énfasis en conceptos que unen a los peruanos. Por ejemplo, las compañías de telefonía están basando gran parte de sus campañas en esta idea. En esta línea también destacan las empresas de bebidas alcohólicas como las de cerveza y las dedicadas a la producción de alimentos.

3. La guía de pautas referencial para el estudio, se puede apreciar en el Anexo No1. 
- Existe un mayor uso y valoración de lo peruano en todo sentido. Lo "peruano» se emplea cada vez más en los planes de marketing y en las campañas publicitarias («lo peruano está de moda»). Se trata de una tendencia que se generaliza cada vez más y que se está convirtiendo en un ingrediente natural de los planes de marketing.

- Ser reconocidos mundialmente por la gastronomía también ha empujado al uso de la diversidad en el marketing y la publicidad. La cocina peruana combina ingredientes y costumbres de diferentes zonas del Perú. Se trata de un elemento que «materializa» la diversidad cultural del país. Esta situación está siendo absorbida y aprovechada por el marketing y la publicidad así, se puede ver ejemplos en algunas campañas de gaseosas, cervezas, bancos, entre otros.

- El uso de la diversidad se ha tornado en un elemento diferenciador y de generación de una relación directa con los clientes. Los consumidores al sentirse representados en las campañas de marketing, generan una relación más estrecha con las empresas y sus marcas.

- La diversidad cultural se puede observar en las comunicaciones de muchas campañas de marketing. Varios de los invitados citan a la marca Benetton como un ejemplo de calibre internacional de una campaña multicultural y mega diversa, con personas de todas las razas. Muchos la consideran como una campaña pionera en el tema.

- Una tendencia clara que se ha identificado es que el consumidor quiere que en la publicidad cada vez exista una mayor presencia de situaciones cotidianas relacionadas con la diversidad cultural. Quiere ver gente "como ellos» pero no en situaciones de pobreza o deslucidas, sino más bien presentados con características estéticas atractivas y deseables. Queda claro que la publicidad genera un vínculo emocional para que conecte con el consumidor. Esto se potencia a través de situaciones y de protagonistas de las pautas publicitarias que sean físicamente parecidos al consumidor.

- Otra tendencia fundamental a tomarse en cuenta en el desarrollo del marketing actual $y$, por ende, de campañas que incluyan la diversidad, es el desarrollo de programas de 360 grados o integrales que incluyan no solo los medios tradicionales de mayor penetración como la televisión, la radio y la prensa; sino también elementos BTL y redes sociales, cuyo empleo es cada vez más fuerte y necesario en los planes de marketing.

En este acápite se solicitó una evaluación acerca del uso de la diversidad por las propias empresas en las que laboran los entrevistados. Así, se tiene:

- Todas las empresas manifiestan emplear la diversidad en mayor o menor medida, sobre todo, en sus planes de marketing, además se expresa que existe la idea de ser más intensivo en su uso en el corto plazo. Adicionalmente, algunas empresas parten de campañas generales que luego son particularizadas en las regiones del país. Las razones más citadas que justifican el uso de la diversidad en el marketing son las siguientes:

\} El conocimiento que las empresas profesan de su público objetivo. Es decir, si una empresa opta por el uso de la diversidad, quiere decir que lo ha investigado y conoce cómo piensa, de dónde proviene, con qué se identifican, entre otros.

3 Llevar las marcas hacia una plataforma más emocional. El uso de la diversidad permite una conexión más profunda con los clientes, ello está sucediendo con algunas empresas que emplean el atributo de la peruanidad en sus campañas $u$ otro elemento concreto que manifieste diversidad y una posibilidad de identificación del público objetivo.

\} Lograr un acercamiento hacia los clientes. Esta es una constante preocupación de los funcionarios de 
marketing, así la diversidad ofrece una veta bastante explotable.

\} Por una evolución en la imagen de las empresas, que están mutando hacia entes organizacionales más cercanos a las personas y las comunidades que forman; además de preocuparse cada vez más por posicionarse como compañías responsables e identificables con las personas.

iii) Tipo de diversidad empleado por las empresas peruanas

Analizando las opiniones de los entrevistados, en el Perú, a la que más atención se presta es a la diversidad de regiones (procedencias de los consumidores y costumbres al respecto). Otras diversidades a tenerse en cuenta son:

- Relacionada con el género. Cabe mencionar que en el marketing cada vez existe una mayor revaloración y reconocimiento de la mujer aunque aún quedan elementos del uso del género femenino en relación con su uso como objeto y elementos de machismo en diferentes niveles socioeconómicos.

- Referente a la edad. El enfoque de los productos hace que existan segmentaciones bastante particulares que implican que se abarque un panorama bastante amplio en lo que a edades respecta.

- La que tiene que ver con la raza. Si bien no existen campañas publicitarias tan explícitas como las de la marca italiana Benetton, en la actualidad si existe cierta apertura a la variedad racial del país lo cual se puede observar en la selección de protagonistas de los comerciales, afiches, catálogos, entre otros.

\section{iv) Rentabilidad económica del uso de la diversidad}

La rentabilidad es un tema fundamental en toda estrategia empresarial, en esta línea los ejecutivos entrevistados manifestaron lo siguiente:

- Todos los entrevistados manifestaron que incluir a la diversidad en sus empresas (sobre todo en sus planes de marketing) fue rentable. La misma no solo se evaluó como económica (calculada con herramientas financieras convencionales) sino también en términos de la imagen de la empresa, de la marca y de su acercamiento al cliente (de evaluación cualitativa aunque, se puede reflejar en la evaluación del posicionamiento de las marcas).

Sin embargo, también se menciona como un aspecto muy relevante a los altos costos de investigación, diseño e implementación del desarrollo de campañas que trabajen el tema de la diversidad. En este sentido, los ejecutivos afirman que para un uso eficiente de la diversidad en los programas de marketing es necesario desarrollar estudios sobre todo cualitativos, que incrementan los costos de las campañas de manera ostensible. Queda claro que una buena investigación relacionada al uso de la diversidad $-\mathrm{O}$ a cualquier tema relacionado con el marketing, el comportamiento del consumidor, entre otros-, siempre implicará un presupuesto elevado. Se trata de sumas altas que no todas las áreas de marketing de las empresas tienen a su disposición.

- En lo que respecta a la publicidad, queda claro que es casi una norma que un comercial antes que "salga al aire», se evalúe cualitativamente para que se puedan corregir y tener comerciales más efectivos y que por lo tanto, van a generar mayores ventas. Actualmente, este proceso es común a toda campaña publicitaria independientemente de si incluya o no elementos relacionados con la diversidad.

- Adicionalmente, existe un consenso en que el uso de la diversidad es más rentable en los públicos masivos. Se debe tener en cuenta, por ejemplo, que el NSE C es el $62 \%$ de la población de Lima Metropolitana. Por otro lado, la rentabilidad en el uso de la misma también se presenta en nichos que pueden sentirse olvidados o desatendidos.

- En cuanto a la evaluación de la rentabilidad de un plan de marketing o de una campaña publicitaria, la evaluación financiera 
es la típica (inversión inicial y flujos descontados a una tasa determinada por la propia empresa en función a su costo de oportunidad).

El uso de la diversidad en el marketing es rentable. La población peruana siente la necesidad de sentirse identificada con los mensajes que recibe y los personajes que se los transmiten. En cuanto a la evaluación de la rentabilidad, fundamentalmente el empleo de la diversidad produce mayores ingresos para las empresas que se reflejan en el aumento de sus ventas, lo cual hace que los flujos a descontar sean cada vez más elevados.

\section{v) Retos o desafíos en torno al uso de la diversidad por las empresas}

En este acápite se intentó tener una opinión acerca de los retos s futuro en el uso de la diversidad por parte de las empresas peruanas. Así, se consideró lo siguiente.

- En primer lugar, se puede afirmar que el reto -en términos comercialescon respecto a la diversidad, es para las multinacionales, dado que sus campañas son globales y bastante generales. Existe una tendencia cada vez más fuerte hacia la particularización con características locales de las mismas. El objetivo es que las campañas adaptadas a ambientes específicos, estén alineadas perfectamente con los objetivos globales de la campaña y la demanda de focalización e identificación local por parte de los consumidores.

Una marca global no tiene mucha flexibilidad para llegar a un público diverso, normalmente están orientadas a un público objetivo bastante específico y no necesariamente todos los consumidores pueden tener acceso a sus campañas y a poder consumirla. Es un reto para este tipo de empresas el incluir la diversidad nacional en su forma de comunicar de forma que además esté alineada con su comportamiento y sus pautas globales.

- Otro reto para las empresas - y que guarda relación con la diversidad- es el desarrollo de más vínculos emocionales con los consumidores. A medida que se trabajen más en las características intangibles de los productos y que permitan que el consumidor se identifique con atributos positivos emocionales. La marca se va a enriquecer para el consumidor y se diferenciará. La diversidad ofrece una clara oportunidad en este sentido.

Actualmente, se presenta una tendencia muy fuerte por parte de muchas empresas por trabajar más campañas sobre la parte emocional. Lo importante es asignar a las marcas beneficios emocionales, sensaciones y situaciones en las cuales las personas puedan identificarse.

- Se cree que las empresas que no sean capaces de evolucionar y responder a los gustos y preferencias para satisfacer las exigencias de los consumidores peruanos que han asumido su diversidad como característica positiva y valiosa; posiblemente - a corto plazo- tengan que replantear esta visión si es que quieren permanecer en el mercado.

- Tomar las medidas necesarias para que el uso de la diversidad no llegue a convertirse en burla $o$ en actos discriminatorios. Es decir, que una campaña no lleve a que un grupo específico sea importunado por el mensaje o contenido del plan de marketing desarrollado.

- Que la creatividad en publicidad y la aplicación en marketing, resalten los beneficios de ser un país multicultural en todos los aspectos.

- La exportación de la diversidad peruana más allá de lo meramente turístico y pintoresco.

Es importante tener en cuenta que se identificó que las empresas tienen una tarea pendiente en el uso de la diversidad como puente de comunicación con los consumidores. Las empresas que más necesitan este tipo de nexo son las transnacionales que diseñan campañas amplias y generales. En la diversidad, este tipo de empresas pueden descubrir ventanas de oportunidad para llegar a sus compradores. En el país, sobre todo las grandes empresas de 
telefonía, han sido capaces de particularizar mensajes hasta independizarlos de las campañas generales y regionales. Esta particularización es una tendencia que cada vez estará más presente. Queda claro que las empresas que emplean la diversidad tienen la posibilidad de mejorar su posicionamiento acercándose más a sus mercados objetivos.

vi) Aporte del auto-reconocimiento de la diversidad por parte de los peruanos

Se desarrolló una breve evaluación acerca de lo que significa que los ejecutivos y los peruanos en general, reconozcan su propia diversidad nacional. El cuestionamiento se organizó en dos ámbitos: aportes para la sociedad y aportes en términos empresariales. Los resultados son los siguientes.

- En términos de sociedad, los entrevistados manifestaron los siguientes aportes:

El reconocimiento da diferencias pero, al mismo tiempo, el encuentro de un sentido de pertenencia al país. Es importante mencionar que existe una presencia fuerte del desarrollo de una adhesión en torno a la nacionalidad y pertenencia a una nación.

\} Conceptualizar al peruano como «diferente» del resto del mundo y, por ende, como especial y único. Existe una opinión que la cultura peruana, debido a su diversidad, es única en el mundo lo que se expresa en culturas, costumbres, comidas, etnias, entre otros. El punto de partida de la diversidad parte de asumirse diferente al resto.

- La sociedad peruana apunta hacia el logro de compartir un sentimiento de orgullo por lo «nuestro» (que incluye la diversidad cultural, racial y social, historia, entre otros). Se puede observar que cada vez más existe una percepción positiva hacia ser peruano.

\} Integración y sensación de inclusión social ya que por muchos años una gran cantidad de peruanos han sido dejados de lado como públicos objetivo y como parte del mercado. En estos momentos se está viviendo una suerte de «democratización» en la oferta de productos y servicios lo que hace que las clases sociales de menor poder adquisitivo se sientan incluidas en la modernidad y el desarrollo.

- En términos empresariales, se pueden mencionar los siguientes aportes:

Conocer la diversidad de los consumidores ayuda a generar mejores productos, mucho más segmentados y adecuados, y por lo tanto, la posibilidad de desarrollar mayores y mejores negocios. Satisfacer a los clientes es una de las normas fundamentales del marketing, el aprovechamiento de la diversidad apunta a ello.

\} Genera una percepción bastante positiva de la marca, porque el consumidor asume que la ésta "piensa en todos». Las marcas están utilizando la diversidad como un concepto que resulta extremadamente poderoso para el logro de un posicionamiento estratégico en el corto, mediano y largo plazo.

\} Permite capitalizar de una manera más estratégica y eficiente el portafolio de marcas con las que una empresa puede contar. Las empresas tienden a segmentar sobre la base de perfiles que cada vez toman más en cuenta la diversidad cultural de los públicos objetivo, así la misma se puede tornar en una variable de segmentación.

\} Presentar una mejor oferta y llegar a un gran sector o a muchos nichos de mercado que pueden haber estado olvidados históricamente por la competencia o por la propia empresa. Así, se logra acercar las marcas a diversos sectores de la población.

\} En cuanto a la diversidad dentro de los equipos de trabajo de marketing, ésta genera una mayor discusión, más puntos de vista y por ende, mejores resultados. Es casi una norma de la administración que equipos diversos pueden generar 
dinámicas de decisiones y opiniones diferentes que pueden devenir en planes de marketing más eficientes $y$ estratégicos.

Los retos en función a la sociedad y en el ámbito empresarial implican caminos positivos sea en la búsqueda de la identidad nacional o de mayores rentabilidades y ventas para las empresas. Pensando en el futuro, el uso de la diversidad al parecer empuja solamente temas positivos.

\section{Experiencias en el uso de la diversidad en el plan de marketing}

Seguidamente, se presentan cuatro experiencias de marketing que toman a la diversidad como ingrediente dentro de su investigación, diseño e implementación. Estos son los siguientes: América Móvil Perú S.A.C, Telefónica del Perú S.A.A, Soda Field y Jockey Plaza Shopping Center.

\section{América Móvil Perú S.A.C .}

América Móvil Perú es parte del grupo mexicano América Móvil S.A. Desde el año 2005, opera en el país bajo la marca registrada Claro. La empresa ofrece a sus clientes servicios de telefonía móvil en cuatro modalidades: prepago, control, postpago y Claro Empresas.

El mercado objetivo abarca al grueso de la población peruana. Se consideran a hombres y mujeres de los niveles socioeconómicos $A, B, C$ y $D$, de todas las regiones del país y de todas las edades.

A inicios de 2006, Claro planteó el objetivo de consolidar su cobertura telefónica en el país y realizar una campaña que lograra revertir la percepción del consumidor que colocaba a Movistar como líder en este atributo.

Se determinaron como objetivos: incrementar las ventas en $50 \%$ con respecto al ejercicio anterior, lograr un crecimiento superior al del mercado en la categoría de telefonía celular, y posicionar a Claro como la empresa de telefonía celular con mayor cobertura en el país, preocupada por el desarrollo del mismo y de sus habitantes, además de mantener un índice de recordación de marca superior al $45 \%$.

Bajo el lema "Claro que tienes más» se empleó una estrategia de oferta de producto altamente competitiva, un aumento de los puntos de venta, motivación a la fuerza de ventas mediante una nueva estructura de comisiones, además de la organización de ferias en distintas ciudades del país, y una ampliación de sus canales de distribución.

Para la campaña publicitaria se desarrolló la idea de "hablarle» al consumidor en su idioma, a través de historias que simulaban situaciones cotidianas con el uso de telefonía y que tenían como escenario lugares representativos de cada región (para ello se contó con especialistas en lingüística e investigadores en geografía, costumbres, trajes típicos, entre otros). El mensaje principal a trasmitir era cómo el atributo de una mayor cobertura ayuda a la telefonía celular a ser un mejor instrumento de comunicación. En la promoción se empleó una estrategia «multimedios», diseñada para generar un alto impacto en el público objetivo de todas las regiones. La campaña se inició en abril de 2006 y culminó en febrero de 2007.

Como resultado Claro creció $72,7 \%$ en el 2006 , las ventas se incrementaron en $62 \%$ con respecto al año anterior, además con respecto a los atributos de marca más valorados por los clientes se logró un $58,2 \%$ de afinidad en cuanto a Cobertura (seguido de Movistar con 54,8\%) y un índice de recordación de marca superior a $50 \%$.

\section{Telefónica del Perú S.A.A ${ }^{5}$.}

Telefónica del Perú está posicionada como líder en la provisión de servicios de telefonía fija, televisión por cable e Internet. En 2004, Telefónica lanzó una campaña llamada Sin darnos cuenta, donde se mostraba los cambios que se habían dado en la sociedad desde la llegada de la compañía y el

4. Sobre la base de Pipoli, Gina (2007).

5. Sobre la base de Pipoli, Gina (2006). Las mejores prácticas del marketing: casos ganadores de los Premios Effie Perú 2007. Lima: Centro de Investigación de la Universidad del Pacífico. 
desarrollo de las comunicaciones en el Perú. Esta campaña cumplió sus objetivos ya que mejoró la imagen, así como la confianza, valoración, simpatía y la intención hacia la empresa.

En 2005, se decidió continuar con la campaña buscando mejorar la relación emocional entre la empresa y la sociedad. El mercado objetivo abarcaba a hombres y mujeres de los niveles socioeconómicos $\mathrm{C}$ y $\mathrm{D}$, de todas las regiones del país y mayores de 18 años. La campaña no se basaba tanto en cambiar la percepción de los peruanos sobre la empresa, sino en mantener o mejorar dicha percepción a través del mensaje de inclusión del peruano en la era de la modernidad. Se determinó como objetivo incrementar en $15 \%$ los niveles promedio de valoración, simpatía, confianza e intención.

Para contextualizar mejor la problemática de la realidad social, se analizó el tema desde el punto de vista de disciplinas como la sociología, la psicología y la antropología. Así, se lograron identificar cuatro conceptos clave para que la empresa pudiera elevar sus resultados anteriores: inclusión, empoderamiento, experiencia y éxito.

Sobre esta base, se desarrolló una línea argumental con tres comerciales. El que obtuvo mayor reconocimiento («La rica Miel») buscó reflejar al peruano/limeño representativo. A través de una incursión al territorio de lo urbanopopular se muestra cómo es la realidad de los conos de Lima y se empieza a destacar en sus comerciales a distintos tipos de usuarios.

La campaña fue lanzada a mediados de 2005 y se utilizó la televisión, que tiene mayor alcance y ámbito nacional, con lo que se aseguraba un gran impacto. Se asignó a la campaña un presupuesto de más de US\$900,000.

La campaña logró cumplir e incluso superar el objetivo programado en valoración y simpatía, la intención revirtió la situación negativa que había obtenido un año antes y la confianza hacia la empresa logró su máximo nivel histórico.

\section{Soda Field ${ }^{6}$}

Kraft Foods Perú S.A. fue constituida en el año 1972 bajo el nombre de F\&R Perú S.A. Veintiún años más tarde, Kraft Foods Perú S.A. adquirió por fusión a las compañías Arturo Field y La Estrella Ltda. para, en el año 1995, modificar su razón social a Nabisco Perú S.A. Cinco años más tarde, la razón social fue nuevamente cambiada a Kraft Foods Perú S.A. ya que se adquirió Nabisco Holding Corp. por parte de Kraft Foods Inc. Actualmente, la empresa se dedica a la producción y comercialización de todo tipo de alimentos procesados para el consumo humano. Sus categorías de alimentos son las siguientes: Galletas saladas, Galletas dulces, Chocolates, Postres en polvo, Bebidas en Polvo, Gelatinas, Artículos de Repostería, Quesos y Salsas; y maneja marcas muy representativas en el imaginario nacional como: Cua Cua, Doña Pepa, Coronita, Charada, Club Social, Oreo y Soda Field.

Con más de 145 años en el mercado peruano, Soda Field es, según la empresa de investigación de mercados CCR, la líder dentro de las Galletas saladas. Desde que Kraft Foods Perú tomó la dirección de Soda Field en el año 2000, la marca siguió siendo recordada como "ícono peruano» que forma parte de la cultura y costumbres culinarias del país. Actualmente, el portafolio de Soda Field consta de dos presentaciones: Soda Field y Soda Field Agua; un nuevo producto que fue lanzado a mediados de 2009 que rescata el sabor de Soda Field, pero que tiene $43 \%$ menos calorías que la presentación original.

«Esta campaña nace para consolidar el vínculo afectivo que existe entre los consumidores y Soda Field. En los últimos años hemos logrado que las familias consideren nuevos momentos de consumo de esta marca, como en el desayuno. Hoy celebramos su liderazgo a través de los años con un mensaje que apela al optimismo, al progreso del país y a la tradición que supone el compartir lo mejor. Nuestro comercial incluye

6. Sobre la base de Soda Field ingresa al segmento de galletas de agua (http://www.deperu.com/notasdeprensa/index.php?subaction =showfull\&id=1244591267\&archive=\&start_from=\&ucat=15) (09/06/2009). 
en esta oportunidad la presencia de destacados peruanos que han sabido dar lo mejor de sí para conseguir el éxito y son sinónimo de orgullo e identificación con lo nacional. [...] Lo que buscamos es seguir apoyando e impulsando un producto que se encuentra identificado con las costumbres y tradiciones tal como lo ha venido haciendo en sus más de 145 años de existencia. Es parte de nuestro compromiso con el país» señaló Julián Baluk, Gerente General de Kraft Foods Perú7. La campaña se denominó «Damos lo Mejor, Damos Soda Field» que apela a la costumbre de los peruanos de dar siempre lo mejor que tienen.

Se contó con la participación de reconocidos artistas nacionales tales como la cantante Damaris Mallma, la actriz Mónica Sánchez y el conjunto musical Grupo 5. Todos ellos formaron parte del comercial televisivo en el cual aparecen recorriendo distintas ciudades del Perú a bordo de un bus llamado Mi Perú, el cual lleva un mensaje de optimismo que se complementa con la costumbre de «dar lo mejor» por parte de los peruanos.

Para intensificar esta campaña que recuerda el liderazgo de Soda Field al público, Kraft Foods Perú lanzó al mercado un nuevo producto: Soda Field Agua, una galleta ligera con un único sabor artesanal. Este lanzamiento de un nuevo producto tuvo dos efectos: por un lado, se apoyó a la campaña madre para poder entrar con fuerza al mercado y por otro lado, ayudó a resaltar el mensaje de que los peruanos siempre dan lo mejor, en este caso, Soda Field Agua.

La campaña constó de los siguientes medios: televisión abierta, televisión por cable, Televisión Local a través de microprogramas de festividades en provincias (Piura, Chiclayo, Arequipa y Trujillo), publicidad exterior (en buses, paneles, tanto en Lima como en provincias); y, actividades BTL. La marca tuvo presencia en fiestas nacionales importantes tales como la Fiesta de San Juan en la ciudad de Iquitos y el Inti Raymi en la ciudad del Cuzco.
«La campana permitió que Soda Field se consolidara como líder dentro del segmento de galletas saladas y permitió subir sus niveles de recordación de marca, así como los distintos parámetros en la evaluación de imagen de marca», recalca Verónika Pardo, entonces Brand Manager - Crackers de Kraft Foods Perú.

\section{Jockey Plaza Shopping Center ${ }^{8}$}

El Jockey Plaza en un centro comercial ubicado en el distrito de Surco, dentro de la capital del Perú, Lima. Fue fundado en el año de 1997 y se trató del primer centro comercial moderno del país con características similares a los malls internacionales (centros comerciales de grandes dimensiones administrados por un ente que arrienda los locales mas no los vende, con una o más «tiendas ancla»). Para inicios del año 2010, la presencia de centros comerciales ha crecido rotundamente no solo al nivel de la capital sino al nivel nacional.

Su área es superior a los 170,000 metros cuadrados y cuenta con más de 200 locatarios. Su público objetivo son los niveles socioeconómicos A, B y C. Para el año 2008 sus ventas fueron del orden de los 480 millones de dólares y la afluencia mensual de público es cercana a los 2.5 millones de visitas .

La campaña Ser Mujer Ser Maravilloso se realizó con la finalidad de rendirle un tributo a la mujer durante el mes de marzo. Se busca homenajear a las mujeres de todas las edades, de todas las razas y de diferentes condiciones económicas.

Lo que se buscó fue formular la interrogante: ¿qué es para ti ser mujer? Con esta idea participaron en la editorial principal de la Revista J (revista del centro comercial), cuatro mujeres reconocidas en el ambiente limeño y cuatro mujeres que no eran personalidades conocidas o famosas. La idea se basa en que las mujeres son todas especiales.

Se montó un estudio fotográfico en el propio centro comercial para que todas las mujeres que quieran participar en la campaña, puedan ser

\footnotetext{
7. http://www.deperu.com/notasdeprensa/index.php?subaction=showfull\&id=1244591267\&archive=\&start_from=\&ucat=15

8. Sobre la base de entrevista con Jimena Caso, Jefa de Marketing del Centro Comercial Jockey Plaza.

9. http://www.accep.org.pe/jockey.pdf.
} 
maquilladas, fotografiadas y al final peguen su foto en un muro en el propio mall adicionando una frase que responde a la pregunta: ¿qué es para ti ser mujer?. Hasta mediados de marzo de 2010 se tiene más de 700 fotos de diferentes mujeres. De esta manera se reconoce a la mujer como especial y clave en la sociedad.

En los primeros meses de 2010, las ventas del centro comercial han crecido en un $20 \%$ con respecto al año pasado. Si bien no se puede asignar este crecimiento únicamente a la campaña, en estos momentos, en los que los consumidores tienen más ofertas de donde escoger, ofrecer un punto de encuentro completo para compras personales, con la familia, entretenimientos y servicios es fundamental. La idea es realizar actividades que involucren a los diferentes clientes del centro comercial y esta campaña aporta decidamente a esto.

Las cuatro experiencias presentadas, emplean a la diversidad desde diferentes puntos de vista orientadas principalmente a la segmentación en la definición de públicos objetivos, es decir, desde la propia definición de los clientes. En las experiencias se puede observar el uso de la diversidad cultural, demográfica y étnica, Además, en la última experiencia se parte la segmentación por género para luego trabajar los tres tipos de diversidad mencionados. Los resultados de las campañas presentadas permiten observar resultados económicos y mercadológicos positivos para las organizaciones que las han desarrollado.

\section{Conclusiones}

Es indudable que el Perú es un país que posee una amplia diversidad cultural. A pesar de que ésta ha suscitado fuertes conflictos y discusiones sociales, no hay que olvidar que también ha sido un factor clave en el «boom económico» del país en los últimos años. Esto se ha debido a que la diversidad existente se ha utilizado como una ventaja competitiva por parte de las empresas peruanas. Esta utilización de la diversidad se evidencia a tal punto que, en el ámbito empresarial, los clásicos grupos económicos ahora comparten escenario con otros nuevos cuyos orígenes son esencialmente provincianos. En este punto se puede concluir que las costumbres y gustos diversos en la sociedad peruana llegan a traspasar a más sectores de la misma; en otras palabras, las preferencias culturales ya no son exclusivas de un sector socio-económico sino que otros sectores de la sociedad han logrado asimilarlas.

En el país, la diversidad es un elemento que está aparentemente permitiendo a su población identificarse con una nacionalidad (la identificación como «peruanos»). La sociedad peruana implícita y explícitamente está tratando de construir elementos integradores - aglutinadores de los ciudadanos como peruanos. Al carecer de éxitos deportivos en deportes masivos, el Perú ha estado huérfano de catalizadores o generadores de pertenencia y de nacionalidad hasta que desde hace más de una década, se habla con inusitada fuerza de la gastronomía y justamente, la misma es el resultado de la diversidad de dicho país en todo sentido (regional, cultural, de procedencias, de herencias, de ascendencias, entre otros). En sí, se puede afirmar que la gastronomía es un triunfo de la diversidad y una clave para entender al Perú actual.

En el presente trabajo se desarrolló un marco teórico cuyo objetivo fue lograr una aproximación al uso de la diversidad en el ámbito empresarial. Para ello, en primer lugar, se presentaron algunas definiciones generales de diversidad. En segundo lugar, se plantearon una serie de ideas consideradas como interesantes para entender el concepto de diversidad en el ámbito empresarial. En tercer lugar, se mostró la aplicación directa de la diversidad en el ámbito empresarial. Por último, se profundizó en el tema de rentabilidad tras el uso de la diversidad en las organizaciones.

Este estudio plantea dos grandes dimensiones en el uso de la diversidad en las organizaciones. La primera dimensión hace referencia al manejo interno («hacia dentro») de la diversidad; algunos autores sostienen que la percepción de los empleados (recursos humanos) de la diversidad en la alta gerencia está positivamente relacionada con la percepción de la performance organizacional. De la misma manera, otros 
autores dan énfasis no en la diversidad per se, sino más bien en un sentido de pertenencia a una cultura. Ellos afirman que una cultura en común (cultura interna de una empresa) ayuda a las personas a darle un sentido a las cosas, y las define como seres humanos.

Las empresas han centrado mucha atención en la dimensión de políticas, sistemas y procesos, han dejado de lado el marco normativo interno. Esto resulta un error; puesto que, la diversidad tiene como elementos fundamentales a las normas culturales y valores. Entonces, dado que la naturaleza de la diversidad involucra tanto normas como valores, para desarrollar una cultura de diversidad e inclusión dentro de la firma es necesario centrarse en estos aspectos. El reconocimiento es el aspecto base para llevar a cabo esta tarea, y del cual se desprenden otros principios básicos: entendimiento mutuo, diversidad de los puntos de vista, confianza e integridad. Todo esto, en conjunto, es la base para fomentar un ambiente de inclusión laboral en las empresas, que a su vez pueda ser medido constantemente para beneficio de la fuerza laboral y por ende, de una empresa que aplique la diversidad dentro de sí misma.

La segunda dimensión viene dado desde el manejo externo («hacia afuera») de la diversidad, en su forma más amplia esto se da cuando, en las estrategias de segmentación del área de Marketing, las empresas hacen uso de la diversidad dentro de los criterios de la definición de un segmento. Dentro de esta perspectiva, los entendidos del tema afirman que la segmentación por etnias puede ser eficiente en costos y puede contribuir al crecimiento, rendimiento y competitividad de la empresa. Sin embargo, los costos en que una empresa incurre para obtener una comunicación directa con su público objetivo pueden ser mayores a los ingresos generados por realizar dicha campaña. Hay que tomar en cuenta que si se desea emplear la diversidad dentro de un programa de Marketing, se debe tomar en cuenta el reconocimiento e inclusión de características étnicas específicas y no estereotípicas. Además, no se debe olvidar que lo relevante, dentro de una campaña publicitaria, es el contenido más no el formato. En definitiva, se debe priorizar la comunicación de los atributos del producto o servicio publicitado; y luego buscar la posibilidad de aprovechar elementos relacionados con la diversidad cultural del público objetivo.

Como último punto importante del marco teórico se tiene a la rentabilidad tras la utilización de la diversidad en las organizaciones. Los resultados del estudio citado, son consistentes y sugieren que la diversidad de la fuerza laboral tiene un efecto positivo sobre el desempeño de la organización. Esta asociación positiva entre diversidad y desarrollo organizacional puede deberse a que los grupos inclusivos sean más talentosos, o que las firmas exitosas puedan dedicar mayores recursos a los temas de diversidad, o se puede deber a una razón dinámica que involucre ambos aspectos. Entonces se puede concluir que existen evidencias de un impacto positivo de la diversidad racial en la fuerza laboral sobre la comunicación, la creatividad y resolución de problemas; que finalmente se traduce en un incremento de la rentabilidad y las ganancias de la firma

Además, esta investigación desarrolló un estudio cualitativo a veinte ejecutivos peruanos, de éste se puede afirmar que la diversidad es un tema presente en el mundo empresarial nacional. Las empresas la están incluyendo cada vez más en sus campañas y están avanzando en planes más segmentados y estratégicamente elaborados. Así mismo, los insigths o conceptos relacionados con la diversidad son cada vez más estudiados y tomados en cuenta en los planes empresariales y de marketing de las empresas. La presentación de los resultados abarca seis temas, de los cuales se concluye lo siguiente.

i) Definición de la diversidad: es un concepto útil dentro de la estrategia de segmentación de las empresas por lo que es relevante en las decisiones de Marketing. Hay consciencia de la importancia de la diversidad dentro del país, y la ubican principalmente en el ámbito cultural.

ii) Uso de la diversidad en el mundo empresarial peruano: En los últimos años, la publicidad hace más énfasis en conceptos que unen a los peruanos. Inclusive existe un mayor uso y valoración de lo "peruano», en campañas gastronómicas por citar 
un ejemplo. El uso de la diversidad se ha convertido en un elemento diferenciador y genera una relación directa con los clientes.

iii) Tipo de diversidad empleado por las empresas peruanas: A la que más atención se presta es a la diversidad de regiones, es decir, a la procedencia de los consumidores y costumbres que ellos poseen. No obstante, también se hace énfasis a la diversidad relacionada con el género, edad y raza.

iv) Rentabilidad económica del uso de la diversidad: Todos los entrevistados manifestaron que incluir la diversidad dentro de sus planes de Marketing fue rentable. Sin embargo, no ésta no sólo se refiere al plano económico sino también en términos de la imagen de la empresa (acercamiento con el cliente).

v) Retos o desafíos en torno al uso de la diversidad de las empresas: Existe una tarea pendiente en el uso de la diversidad como puente de comunicación con los consumidores. Las empresas que más necesitan este nexo son las transnacionales que diseñan campañas amplias y globales.

vi) Aporte del auto-reconocimiento de la diversidad por parte de los peruanos: Se debe conceptualizar al peruano como "diferente» al resto del mundo, esto debido a su gran diversidad que lo hace único. Asimismo, se debe conocer la diversidad de los consumidores peruanos; ya que, ayuda a generar mejores productos, mucho más segmentados y adecuados.

En otro aspecto, empleando las cinco reglas de Gina A. Rudan (2004) en las cuatro experiencias presentadas en este trabajo, se observa una clara integración mediante el diseño de productos y campañas pensadas para satisfacer las nuevas necesidades de los clientes identificados, los productos y campañas se basan en investigaciones de mercados ad hoc. Las experiencias además buscan llegar a sus públicos objetivos en sus propios contextos culturales. Las compañías responsables de las cuatro experiencias presentadas tratan de influir directamente en la percepción de sus consumidores y de la sociedad en general. Asimismo, las organizaciones presentadas tratan de agruparse con los expertos en el tema de la diversidad a diferentes niveles

Se puede concluir que los altos ejecutivos de la mayoría de empresas entrevistadas toman en cuenta a la diversidad dentro de sus planes de Marketing, porque son conscientes que de esta forma llegan a establecer un vínculo más estrecho entre el consumidor y la empresa. Estos ejecutivos toman en consideración a las dos dimensiones del manejo de la diversidad planteadas en este estudio: el interno y el externo, dentro de sus organizaciones. Esta utilización de la diversidad en el ámbito empresarial puede suscitar un aumento en la rentabilidad no sólo económica, sino también en la imagen que tiene el consumidor de la empresa. Este hecho se puede evidenciar empíricamente en las cuatro experiencias en el uso de la diversidad en el plan de Marketing que se ha desarrollado en el quinta sección del presente trabajo. Estos cuatro casos han empleado la diversidad de una manera eficiente tanto «hacia dentro» como «hacia fuera» y han logrado resultados positivas en sus campañas publicitarias.

Finalmente, se puede afirmar que el uso de la diversidad en el mundo empresarial es un tema vigente y de alto potencial de estudio y aplicación. Además, se plantea el desarrollo de estudios que profundicen los temas esgrimidos en este texto, para un mejor conocimiento del tema tanto académica como empresarialmente. 


\section{BIBLIOGRAFÍA}

ASOCIACION DE CENTROS COMERCIALES Y DE ENTRETENIMIENTO DEL PERÚ

S.f. http://www.accep.org.pe/jockey.pdf.

ALLEN, R, G. Dawson, K. Wheatley y Ch. White

2007 Perceived diversity and organizational performance. The University of Tennessee at Chattanooga, Chattanooga, Tennessee, USA. Aceptado el 9 de mayo de 2007.

ARELLANO R. y D. Burgos

2004 Ciudad de los Reyes, de los Chávez, Quispe... Lima: Empresa Periodística Nacional.

ARELLANO, R.

2009 «Tres Cholos». En Diario El Comercio 31 de julio de 2009.

AVERY, D.R. y K. M. Thomas

2004 «Blending Content and Contact: The Roles of Diversity Curriculum and Campus Heterogeneity in Fostering Diversity Management Competency», Academy of Management Learning and Education, 3 (4): pp. 380-96.

BENSCHOP, Y.

2001 «Pride Prejudice \& Performance: Relations between HRM, Diversity \& Performance», International Journal of Human Resource Management, 12(7): pp. 1166-81.

BRATTER, Jenifer y Tukufu Zuberi

2001 The Demography of Difference: Shifting Trends of Racial Diversity and Interracial Marriage, 1960-1990. Race and Society 4: pp. 133-148.

BRYAN, G.

2000 «Individual and Organizational Accountabilities Reducing Stereotypes and Prejudice with the Workplace», Diversity Factor, 8(2): pp. 14-19.

BURGOS, D,

2008 «Use and Abuse of Cultural Elements in Multicultural Advertising». Journal of Advertising Research, junio de 2008.

CALTON, J. M. y N. B. Kurland

1996 «A Theory of Stakeholder Enabling: Giving Voice to An Emerging Postmodern Praxis of Organizational Discourse», in D. M. Boje, R. P. Gephart and T. J. Thatchenkery (eds.), Postmodern Management and Organization Theory (Sage, Thousand Oaks), pp. 154-177.

COX, T. H.

2001 Creating the Multicultural Organization (Jossey-Bass, San Francisco).
Cox y Blake

1991 «Managing Cultural Diversity: Implications for Organizational Competitiveness», Academy of Management Journal, 5(3): pp. 45-56.

CUI, Geng

2002 «Marketplace diversity and cost-effective marketing strategies». Journal of Consumer Marketing, Vol. 19, No. 1, pp. 54-73.

DAHLIN, K.B., L. R. Weingart y P. J. Hinds

2005 «Team Diversity and Information Use», Academy of Management Journal, 48(6):1107: p. 23.

DENTON, Keith

1997 «Down with diversity (at least some of it): a case for cultural identity». Empowerment in Organizations, Vol. 5 No. 4, MCB University Press: pp. 170-175.

\section{DEPERU}

2009 http://www.deperu.com/notasdeprensa/index. php? subaction=showfull\&id $=1244591267 \&$ arc hive $=\&$ start_from $=\&$ ucat $=15$. Consultado el 9 de junio de 2012 .

DEVINE, F., T. Baum, N. Hearns y A. Devine

2007 «Cultural Diversity in Hospitality Work: The Northern Ireland Experience», International Journal of Human Resource Management, 18 (2): pp. 333-49.

DIETZ, Gunther

2007 «Keyword: Cultural Diversity, A guide through the Debate»: p. 8.

DONKIN, R.

2007 Learn to Keep an Open Mind, Human Resources, London.

DOUGLAS, P. H.

2008 «Afinity Groups Catalyst for Inclusive Organizations», Employment Relations Today (Willey), 34 (4): pp. 11-18.

EARLEY, P.C. y Mosakowski, E.

2004 «Cultural Intelligence», Harvard Business Review. 82(10): pp. 139-46.

EGGERS, Mitchel

2008 «Multicultural Research». Marketing Research; Fall 2008, Vol. 20 Issue 3, p. 5.

FORBES, L.H.

2008 «Diversity is Key to a World-class Organization», Leadership \& Management in Engineering. 8(1): pp. 11-15. 
GARCIA VEGA, Emilio

2007 «La nueva clase corporativa peruana». En Business: negocios en el Perú; Universidad San Marín de Porres.

GILBERT, J. A., y J. M. Ivancevich

2000 «Valuing Diversity: A Tale of Two Organizations», Academy of Management Executive 14(1), pp. 93-105.

GOUILLART, F. J. y J. N. Kelly

1995 Transforming the Organization (McGraw-Hill, New York).

GROSCH, S. L. Doherty

1999 «Diversity Management in Practice», International Journal of Contemporary Hospitality Management, 11(6): pp. 262-68.

HABERMAS, J.

1996 Die Einbeziehung des Anderen. Studien zur politischen Theorie (Suhrkamp, Frankfurt am Main).

HEAMES, J.T., M. G. Harvey y D. Treadway

2006 «Status inconsistency: An Antecedent to Bullying Behavior in Groups», International Journal of Human Resource Management, 17(2): pp. 348-61.

HELGESEN, S.

1990 The Female Advantage: Women's Ways of Leadership (Doubleday, New York).

HERRING, Cedric

2009 «Does Diversity Pay?: Race, Gender, and the Business Case for Diversity», American Sociological Review, Vol. 74, No. 2 (Apr., 2009), pp. 208-224.

HEWLETT, S.A., C. B. Luce y C. West

2005 «Leadership in Your Midst: Tapping the Hidden Strenght of Minority Exployees», Harvard Business Review, 83(11): pp. 74-82.

HITT, Michael

2009 Strategic management: competitiveness and globalization: concepts and cases. SouthWestern Cengage Learning.

HONNETH, A.

1994 Kampf um Anerkennung (Suhrkamp, Frankfurt am Main); English: Struggle for Recognition (MIT Press, Boston).

HUBBARD, Edward E.

1997 Measuring Diversity Results. Petaluma, CA: Global Insights.
2004 The Diversity Scorecard: Evaluating the Impact of Diversity on Organizational Performance. Burlington, MA: Elsevier ButterworthHeinemann.

KALLEBERG, Arne L., David Knoke y Peter Marsden 2001 NationalOrganizations Survey (NOS), 1996-1997 [Computer file]. ICPSR version. Minneapolis, MN: University of Minnesota Center for Survey Research [producer], 1997. Ann Arbor, MI: Inter-university Consortium for Political and Social Research [distributor], 2001.

\section{KALUF, Cecilia}

2005 «Diversidad Cultural: Materiales para la formación docente y el trabajo de aula». Organización de las Naciones Unidas para la Educación, la Ciencia y la Cultura. Santiago de Chile, pp. 23.

KANTER, R. M.

1997 «Restoring People to the Heart of The Organization of the Future», in F. Hesslebein, M. Goldsmith and R. Beckhard (eds.), The Organization of the Future (Jossey-Bass, San Francisco), pp. 139-150.

KOTLER, Philip y Gary Armstrong

2013 Marketing : An Introduction. Prentice Hall,

2012 Marketing Management. Prentice Hall.

KOTTER, J. P.

1996 Leading Change (Harvard Business School Press, Boston, MA).

MAAK, T.

1999 Die Wirtschaft der Burgergesellschaft (Haupt, Bern, Stuttgart, Wien).

MCDONALD, Darren

2003 «Strategic Human Resource Management Approach to workforce diversity in Japan-Harnessing Corporate Cultura for Organizational Competitiveness». Global Business Review: p.100

MEDINA, Oswaldo

2000 El achoramiento: una interpretación sociológica. Apuntes de Estudio No. 38. Lima: CIUP.

MILLER, G.E. y J. I. A. Rowney

1999 «Workplace Diversity Management in a Multicultural Society», Women in Management Review, 14(8): pp. 307-15.

MOORTHY, R. S., R. T. de George, T. Donaldson, W. J. Ellos, R. C. Solomon y R. B. Textor 
1998

Uncompromising

Integrity.

Motorola's Global Challenge (Motorola University Press, Schaumburg, IL).

MOR-BARAK, M. E. y D. A. Cherin

1998 Atool to expand organizational understandingof workforce diversity: Exploring a measure of inclusion-exclusion. Administration in Social Work, 22 (1),47-64

NEGRON, Bárbara; Mane Nett, Ignacio Walket y Joé Weinstein

2005 Diversidad cultural : el valor de la diferencia. Santiago, Chile : LOM Editores.

NG, E.S.W. y Burke, R.J.

2005 «Person- Organization Fit and the War for Talent: Does Diversity Management Make a Difference?», International Journal of Human Resource Management, 16(7): pp. 1195-1210.

NUGENT, Guillermo

1992 El laberinto de la choledad. Fundación Friedrich Ebert, 1992.

NWANKWO Sonny y Andrew Lindridge

1998 «Marketing to ethnic minorities in Britain», Journal of Marketing Practice: Applied Marketing Science, Vol. 4 No.7, pp. 200-216.

NYAMBEGERA, S.M.

2002 «Ethnicity and Human Resource Management practice in Sub-Saharan Africa: the Relevance of Managing Diversity Discourse», International Journal of Human Resource Management, 13(7): pp. 1077-90.

O'FLYNN, Jannine, André Sammartino, Karen Lau y Professor Stephen Nicholas

2001 «Adding value trough HRM: a business model for diversity management». Australian centre for international business.

OLLAPALLY, Anita y Jyotsna Bhatnagar

2009 «The Holistic Approach to Diversity Management: HR Implications». Indian Journal of Industrial Relations, vol 44, No 3. Corporate Social Responsibility, pp. 454-472.

PIPOLI, Gina

2007 Las mejores prácticas del marketing: casos ganadores de los Premios Effie Perú 2007. Lima: Centro de Investigación de la Universidad del Pacífico.

2006 Las mejores prácticas del marketing: casos ganadores de los Premios Effie Perú 2007. Lima: Centro de Investigación de la Universidad del Pacífico.
PLESS, Nicola M. y Thomas Maak

2004 Building an Inclusive Diversity Culture: Principles, Processes and Practice, Journal of Business Ethics, Vol. 54, No. 2 (Oct., 2004), pp. 129-147.

\section{QUEENSBOROUGH COMMUNITY COLLEGE}

S.f. «Definition for Diversity». New York. Extraído el 08 de mayo de 2013. http://www.qcc.cuny. edu/diversity/definition.html.

ROBINSON, G. y K. Dechant

1997 «Building a Business Case for Diversity», Academy of Management Executive, 11(3): pp. 21-31.

\section{RUDAN, Gina}

2004 «Five simple rules for launching a multicultural strategy». Tactics, agosto de 2004. p. 19.

SCHMIDT, Patrick

2004 «An approach to diversity training in Canada». Industrial and Commercial Training Volume 36. Number 4. Emerald Group Publishing Limited. pp. 148-152.

SHARP PAINE, L.

1997 «Integrity», in P. H. Werhane and R. E. Freeman (eds.), The Blackwell Encyclopedic Dictionary of Business Ethics (Blackwell, Malden, MA: Oxford), pp. 335-337.

SKERRY, Peter

2002 «Beyond Sushiology: Does Diversity Work?». Brookings Review 20: pp. 20-23.

SOLOMON, R. C.

1999 A Better Way to Think About Business. How Personal Integrity Leads to Corporate Success (Oxford University Press, New York, Oxford).

SUB, S. y M. Kleiner

2008 «Dissemination of Diversity Management in Germany: A New Institutionalist Approach», European Management Journal, 26(1): pp. 3547.

THOMAS, A. D. y A. Kanji

2004 «IBMs Diversity Strategy: Bridging the Workplace and the Market Place», Harvard Business School Case, 9-405-044, Nov 17: pp. 1-23. https://harvardbusinessonline.hbsp. harvard.edu/b02/.

THOMAS, D. A. y J. J. Gabarro

1999 Breaking Through: The Making of Minority Executives in Corporate America (Harvard Business School Press, Boston, MA). 
THORNELECLAIR, D., O. C. Ferrell y J. P. Fraedrich

1998 Integrity Management (University of Tampa Press, Tampa, FL).

TITINGER, Daniel

2006 Dios es Peruano Historias reales para creer en un país. Lima: Planeta.

TSUI, A.S., T. D. Egan, y Charles A. O'reilly.

1992 «Being Different: Relational Demography and Organizational Attachment». Administrative Science Quarterly 37: pp. 549-579.

VARGAS LLOSA, Mario

1969 Conversación en la Catedral. PEISA.
VEDPURISWAT, A.V.

2008 «The Power of Differences», Indian Management, 47 (1). Enero: pp. 76-83.

WHITE, M.B.

2000 «Are We There Yet?», Diversity Factor, 8(4): pp. 2-6.

WILLIAMS, R. S.

1998 Performance Management. Perspecitves on Employee Performance (International Thomson Busi- ness Press, London). 


\section{Guía de pautas para las entrevistas en profundidad a ejecutivos}

- ¿Qué es diversidad para usted?

- En lo que se refiere al uso de la diversidad en el mundo empresarial peruano: ¿qué está sucediendo en el Perú, qué cambios y permanencias se presentan en lo que se refiere al aprovechamiento de la diversidad cultural peruana?

- Cuánto aporta a los peruanos reconocer su diversidad.

\} En términos de sociedad.

\} En términos empresariales.

- Su empresa incluye aspectos relacionados con la diversidad de la sociedad peruana. ¿Por qué?

- ¿Qué tipo de diversidad incluye su empresa en sus labores (raza, género, identidad sexual, regiones, clases sociales, edad, entre otros)?

- ¿Podría darnos un ejemplo del uso de la diversidad en su empresa?

- Cuán rentable económicamente resulta incluir la diversidad en las empresas.

- Por favor, de ejemplos empresariales peruanos de interés del uso de la diversidad.

- ¿Qué retos o desafíos en torno a la diversidad de las empresas identifica?

- ¿Qué otros temas de interés existen con respecto al uso de la diversidad en el ámbito empresarial peruano? 